\title{
Facebook Surveillance of Former Romantic Partners: Associations with PostBreakup Recovery and Personal Growth
}

\author{
Tara C. Marshall, Ph.D.
}

\begin{abstract}
Previous research has found that continuing offline contact with an ex-romantic partner following a breakup may disrupt emotional recovery. The present study examined whether continuing online contact with an expartner through remaining Facebook friends and/or engaging in surveillance of the ex-partner's Facebook page inhibited postbreakup adjustment and growth above and beyond offline contact. Analysis of the data provided by 464 participants revealed that Facebook surveillance was associated with greater current distress over the breakup, more negative feelings, sexual desire, and longing for the ex-partner, and lower personal growth. Participants who remained Facebook friends with the ex-partner, relative to those who did not remain Facebook friends, reported less negative feelings, sexual desire, and longing for the former partner, but lower personal growth. All of these results emerged after controlling for offline contact, personality traits, and characteristics of the former relationship and breakup that tend to predict postbreakup adjustment. Overall, these findings suggest that exposure to an ex-partner through Facebook may obstruct the process of healing and moving on from a past relationship.
\end{abstract}

\section{Introduction}

$\mathbf{W}$ ITH MORE THAN 900 million active users, Facebook is currently the world's most popular social networking website. The two most cited reasons for using Facebook are to keep in touch with others and to surreptitiously monitor their activities. ${ }^{1}$ Not only do people use Facebook to monitor the activities of current romantic partners, ${ }^{2}$ but as many as onethird use Facebook to keep tabs on former romantic partners. ${ }^{3}$ While Facebook surveillance of ex-partners has been linked to negative outcomes such as online and offline relational intrusion, ${ }^{4}$ the potential for Facebook contact and surveillance to disrupt emotional recovery and growth following a breakup has received little research attention. The current study sought to fill this research gap by examining whether remaining Facebook friends with a former partner and checking his or her Facebook profile is associated with continuing breakup-related distress, negative feelings, desire for the ex-partner, and inhibited personal growth.

\section{Facebook surveillance of former romantic partners}

Many of the features that make Facebook attractive to its users-easy, free, and anonymous access to information about others - can also facilitate online monitoring behavior.
Excessively checking others' Facebook profiles has been variously referred to as interpersonal electronic surveillance, ${ }^{5}$ Facebook surveillance, ${ }^{2}$ or, more colloquially, as "Facebook stalking." In particular, people may use Facebook to keep tabs on an ex-partner's current activities by checking his or her status updates, wall posts, comments, and photos; even if one is no longer Facebook friends with an ex-partner, publicly available information-such as a profile photo and list of friends - can still provide a rough approximation of the expartner's ongoing activities. Recent estimates have suggested that one-half to two-thirds of people have made contact with an ex-partner through Facebook, ${ }^{3,4}$ and that over half admit to having looked through an ex-partner's photos to find pictures of an ex-partner with a new romantic partner. ${ }^{4}$ Not only is Facebook surveillance of ex-partners relatively common, then, but people who engage in it tend to perceive it as harmless. ${ }^{6}$

Other research suggests, however, that Facebook may facilitate behaviors associated with obsessive relational intrusion - the unwanted pursuit of an intimate relationship, particularly with an ex-romantic partner. ${ }^{7}$ Although Facebook surveillance falls on the mild end of the spectrum of relational intrusion, ${ }^{3}$ research has found that monitoring an ex-partner's Facebook photos and other forms of covert

Department of Psychology, School of Social Sciences, Brunel University, Uxbridge, United Kingdom. 
provocation (such as writing a status update to make an expartner jealous) is associated with an increased likelihood of engaging in offline obsessive relational intrusion (e.g., showing up at the ex-partner's classroom or workplace). ${ }^{4}$ Even for individuals who do not engage in relational intrusion, monitoring an ex-partner's online behavior may increase distress over the breakup and prolong pining for the former partner. For example, looking at an ex-partner's Facebook photos may renew desire for the former partner, or it may be upsetting to discover through Facebook that an ex-partner is involved in a new relationship.

The present study examined whether online exposure to a former romantic partner contributed to breakup recovery and growth above and beyond offline exposure. Previous research has established that offline contact is associated with poorer postbreakup functioning; for example, almost half of university students who have experienced a breakup continue to see or talk with their former partner, ${ }^{8,9}$ even though this contact is associated with greater sadness and love for the ex-partner. ${ }^{10}$ From the perspective of social network analysis, ${ }^{11}$ maintaining offline contact with an ex-partner may preserve a strong-tie contact-frequent, reciprocal, and close contact-that ultimately inhibits breakup recovery. On the other hand, remaining Facebook friends with an ex-partner and/or engaging in surveillance of his or her Facebook page may maintain a weak-tie contact-infrequent, nonreciprocal, and casual contact. Weak ties can provide access to information that may not be obtained through strong ties, ${ }^{12}$ such as information obtained through Facebook about the expartner's current activities. Such weak-tie contact may therefore sustain exposure to the ex-partner even in the absence of offline contact, potentially prolonging distress and longing for the former partner. The purpose of the present study was to examine whether weak-tie contact through Facebook sufficiently contributed to postbreakup functioning beyond strong-tie contact. This study also examined whether online contact was negatively related to breakup recovery and growth over and above certain personality traits (selfesteem, attachment style) and characteristics of the former relationship and breakup (e.g., feelings for the partner before the breakup, time since the breakup occurred) that consistently predict postbreakup adjustment. ${ }^{8,13}$ The following hypotheses were tested:

Hypothesis 1: People who remain Facebook friends with an ex-partner will experience poorer breakup adjustment and growth relative to those who do not remain Facebook friends.

Hypothesis 2: Facebook surveillance of an ex-partner will be negatively related to breakup adjustment and growth.

\section{Method}

\section{Participants}

Four hundred and sixty-four participants (84 percent female; $M_{\text {age }}=21.36, S D=5.49$ ) were recruited by posting links to an online survey on several psychology survey-hosting websites (Social Psychology Network Online Social Psychology Studies, Psychological Research on the Net, and the intranet at the author's university). Eighty-seven percent were American, 7 percent were European, 2 percent were Canadian, 2 percent were Latin American, and the remainder were an international mix. Sixty percent of participants were cur- rently working toward an undergraduate degree, 8 percent had completed an undergraduate or higher degree, and the remaining 33 percent had completed high school or A-levels. Forty-eight percent of participants were currently single; of those involved in a romantic relationship, 71 percent were exclusively dating their current partner, 8 percent were cohabitating, 8 percent were married, 7 percent were engaged, and 7 percent were nonexclusively dating. Current relationship status was included in the following analyses as an effect-coded variable ( $1=$ currently involved,$-1=$ single).

\section{Procedure and Materials}

It was stated at the beginning of the survey that participants must have a Facebook account and have experienced at least one relationship breakup with someone who also has a Facebook account to be included in the study. Several questions at the end of the survey addressed demographic variables and current relationship status. Cronbach's alpha coefficients for the following scales are reported in Table 1.

Personality variables. Self-esteem was measured with the 10-item Rosenberg Self-Esteem Inventory. ${ }^{14}$ The Experiences in Close Relationships-Revised scale ${ }^{15}$ consists of 18 items that measure attachment anxiety and 18 items that measure attachment avoidance. Responses on both scales were measured with a 5-point Likert scale anchored with Strongly Disagree (1) and Strongly Agree (5).

Characteristics of the former relationship and breakup. Participants were asked to recall a distressing romantic breakup with someone whom they knew had a Facebook account. They indicated the status of the relationship before the breakup (nonexclusive dating, exclusive dating, cohabitating, engaged, or married), the length of the relationship, and how much time had passed since the breakup occurred. To assess feelings for the ex-partner right before the breakup, participants completed the six-item short-form of the

Table 1. Means, Standard Deviations, AND CRONBACH'S $\alpha$ COEFFICIENTS

\begin{tabular}{lrrc}
\hline & & $\begin{array}{r}\text { Standard } \\
\text { deviation }\end{array}$ & $\begin{array}{c}\text { Cronbach's } \\
\alpha\end{array}$ \\
\hline Age & 21.36 & 5.49 & - \\
Self-esteem & 38.86 & 8.14 & 0.91 \\
Anxiety & 48.28 & 14.59 & 0.92 \\
Avoidance & 41.09 & 13.25 & 0.92 \\
Relationship length (weeks) & 85.84 & 110.14 & - \\
Feelings before breakup & 28.11 & 7.63 & 0.87 \\
Breakup distress & 51.21 & 17.53 & 0.95 \\
Time since breakup (weeks) & 85.58 & 113.70 & - \\
Minutes per day & 87.46 & 131.69 & - \\
$\quad$ on Facebook & & & \\
Number of & 561.34 & 701.63 & - \\
$\quad$ Facebook friends & & & \\
Facebook surveillance & 6.29 & 4.04 & 0.71 \\
Current distress & 13.89 & 6.65 & 0.88 \\
Negative feelings & 17.77 & 8.92 & 0.91 \\
$\quad$ for ex-partner & & & \\
Desire for ex-partner & 6.27 & 3.85 & 0.90 \\
Longing for ex-partner & 13.84 & 8.09 & 0.94 \\
Personal growth & 67.48 & 22.40 & 0.96 \\
\hline
\end{tabular}


Perceived Relationship Quality Components Inventory, ${ }^{16}$ which assesses satisfaction, intimacy, trust, commitment, passion, and love. Two additional items were included that measured the degree of emotional involvement and sexual desire felt for the partner right before the breakup. Participants then indicated which partner initiated the breakup ("I did," "My partner did," or "We both did"). In the following analyses, initiator of the breakup was included as an effect-coded variable ( $1=$ partner initiated, $-1=\mathrm{I}$ initiated/we both initiated). Next, they wrote a description of the circumstances surrounding the end of the relationship, and completed the 16-item Breakup Distress Scale. ${ }^{8}$ The instructions of this scale were modified to ask participants to recall the emotional distress they experienced immediately after the breakup occurred. Responses to this scale and to the measure of feelings for the partner before the breakup were rated on a 5-point Likert scale anchored with Not at all (1), A moderate amount (3), and A great deal (5).

Offline and online contact with the ex-partner. Participants were asked if they currently had offline contact with the expartner and were Facebook friends with the ex-partner. These two variables were effect coded $(1=$ Yes, $-1=$ No). Facebook surveillance was assessed with two items that were equally applicable to people who were currently Facebook friends with the ex-partner and those who were not: "How often do you look at your ex-partner's Facebook page?" and "How often do you look at your ex-partner's list of Facebook friends?" These items were rated on a 9-point scale ranging from Never (1) to Several times a day (9). Participants were also asked how many Facebook friends they had and how much time in minutes they spent on Facebook on a typical day.

Breakup adjustment and growth. Current distress over the breakup was assessed with six items (e.g., "How much distress do you currently feel concerning the breakup?" and "How heartbroken are you when you think about the breakup?"). Participants indicated the extent of their negative feelings toward the ex-partner by rating how much anger, disappointment, confusion, hate, betrayal, hurt, frustration, and sadness they currently felt (selected in part from other work $^{10,17}$ ). Sexual desire for the ex-partner included items measuring lust, sexual arousal, and desire. All of the items measuring current distress, negative feelings, and sexual desire were rated on a 5-point Likert scale anchored with Not at all (1), A moderate amount (3), and A great deal (5). Longing for the ex-partner was assessed with four items ${ }^{18}$ (e.g., "I am still in love with my ex-partner") combined with three additional items $^{13}$ (e.g., "Everything seems to remind me of my expartner"). These items were rated on a 5-point Likert scale ranging from Strongly Disagree (1) to Strongly Agree (5). Finally, personal growth was measured by modifying the instructions of the 21-item Post-traumatic Growth Inventory ${ }^{19,20}$ to ask participants how much life change they had experienced in different areas as a result of their breakup (e.g., "I developed new interests"). These items were rated with a 5-point Likert scale anchored with Not at all (1) and A great deal (5).

\section{Results}

\section{Descriptive statistics}

Means and standard deviations are reported in Table 1, and Pearson's correlations in Table 2. Additional analyses revealed that 82 percent of participants had been exclusively dating their former partner before the breakup, 38 percent indicated that their partner had initiated the breakup, and 44 percent indicated that they continued to have some offline contact with the ex-partner. Of the latter participants, 73 percent described themselves as close or casual friends with the ex-partner, suggesting a strong-tie contact. Fifty-seven percent of all participants reported that they were still Facebook friends with the ex-partner; of these participants, over 90 percent indicated that the ex-partner's Facebook wall, photo albums, profile photo, status updates, and list of friends were visible to them. Forty-six percent of participants who were still Facebook friends with the ex-partner indicated that they exchanged Facebook messages and comments with this former partner (81 percent of whom also maintained offline contact); of the 54 percent who remained Facebook friends with the ex-partner, but did not exchange any Facebook-mediated communication, 53 percent did not maintain offline contact, suggesting a weak-tie contact. Of the people who were not Facebook friends with the ex-partner, 25 percent reported that they had defriended the ex-partner, 12 percent reported that the ex-partner had defriended them, and 6 percent reported that they had never been Facebook friends with the ex-partner at any point in time. Less than 50 percent of these participants had access to their ex-partner's Facebook wall, photo albums, and status updates, but 86 percent could see their ex-partner's profile photo, and 72 percent could see their ex-partner's list of friends. That the measure of Facebook surveillance was based on the frequency of checking the ex-partner's Facebook page (which includes the profile photo) and friends list is therefore consistent with the visibility of these elements even for those participants who were not currently Facebook friends with the ex-partner.

\section{Regression analyses}

Table 3 reports the results of a series of hierarchical regression analyses that tested the predictors of current distress, negative feelings, sexual desire, longing for the ex-partner, and personal growth. For each analysis, the demographic and personality variables (age, sex, anxiety, avoidance, selfesteem), characteristics of the former relationship and breakup (length of the past relationship, feelings before the breakup, initiator status, breakup distress, length of time since the breakup, and current involvement), indices of Facebook usage (number of Facebook friends, average time per day in minutes spent on Facebook), and offline contact with the ex-partner were entered in Step 1. Average time per day spent on Facebook did not significantly contribute to any of the models, and was therefore removed. The key Facebook variables-whether participants were currently Facebook friends with the ex-partner and Facebook surveillance-were added in Step 2.

As seen in Table 3, many of the personality traits and characteristics of the past relationship and breakup entered at Step 1 significantly contributed to variance in the dependent variables. Additionally, offline contact was positively associated with current distress, desire, and longing for the expartner. More pivotal to the present study, the two Facebook variables entered at Step 2 significantly contributed to variance in the dependent variables over and above the 


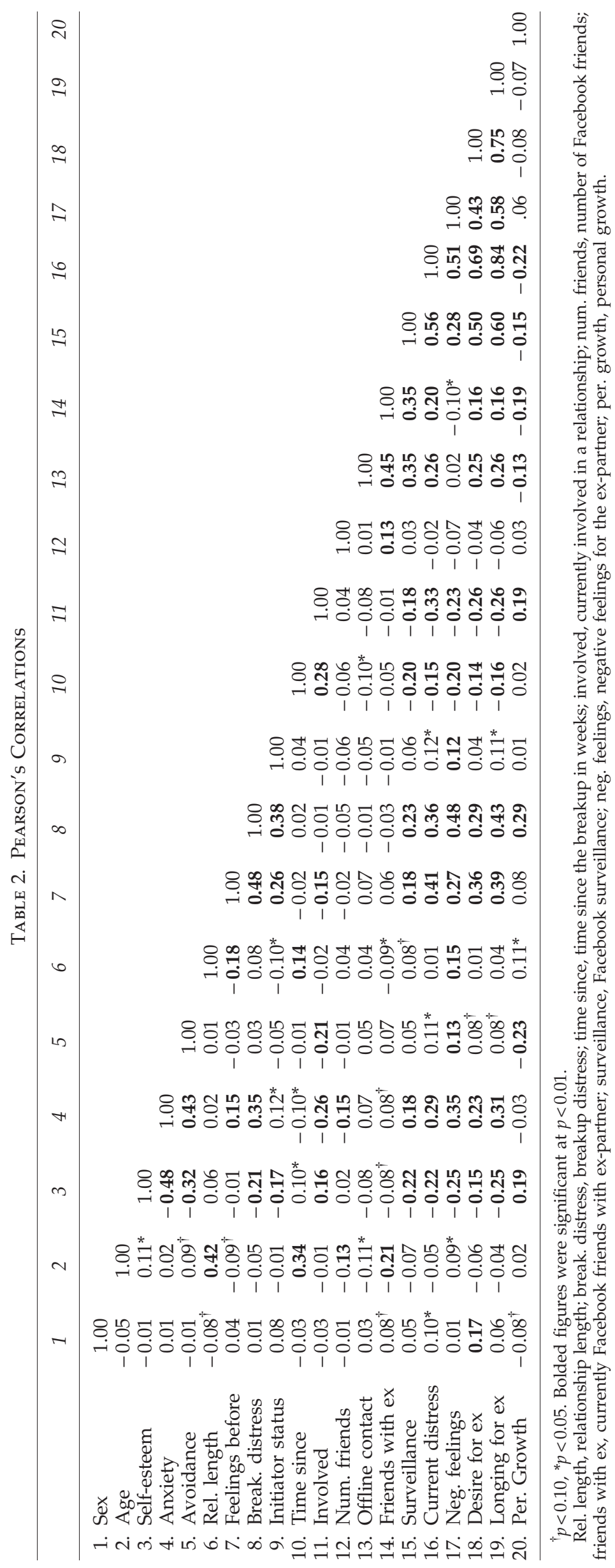


Table 3. Standardized Regression Coefficients

\begin{tabular}{|c|c|c|c|c|c|}
\hline & $\begin{array}{l}\text { Current } \\
\text { distress }\end{array}$ & $\begin{array}{l}\text { Negative } \\
\text { feelings }\end{array}$ & $\begin{array}{c}\text { Desire } \\
\text { for ex-partner }\end{array}$ & $\begin{array}{c}\text { Longing } \\
\text { for ex-partner }\end{array}$ & $\begin{array}{l}\text { Personal } \\
\text { growth }\end{array}$ \\
\hline \multicolumn{6}{|l|}{ Step 1} \\
\hline Sex & 0.03 & 0.02 & $0.14^{* *}$ & 0.01 & -0.02 \\
\hline Age & $0.12^{*}$ & $0.13^{*}$ & 0.06 & $0.10^{*}$ & -0.01 \\
\hline Self-esteem & $-0.10^{*}$ & $-0.13^{*}$ & -0.07 & $-0.13^{* *}$ & $0.19^{* *}$ \\
\hline Anxiety & $0.09^{\dagger}$ & 0.08 & 0.06 & $0.10^{\dagger}$ & 0.06 \\
\hline Avoidance & -0.02 & -0.02 & 0.01 & -0.07 & $-0.20^{* * *}$ \\
\hline Relationship length (weeks) & -0.04 & $0.13^{*}$ & -0.01 & -0.01 & 0.08 \\
\hline Feelings before breakup & $0.30^{* * *}$ & 0.06 & $0.27^{* * *}$ & $0.21^{* * *}$ & $-0.10^{\dagger}$ \\
\hline Breakup distress & $0.22^{* *}$ & $0.40^{* * *}$ & $0.16^{* *}$ & $0.32^{* * *}$ & $0.36^{* * *}$ \\
\hline Initiator status & -0.07 & -0.03 & $-0.13^{* *}$ & $-0.09^{\dagger}$ & -0.06 \\
\hline Time since breakup (weeks) & $-0.12^{* *}$ & $-0.22^{* * *}$ & $-0.12^{*}$ & $-0.14^{* *}$ & -0.07 \\
\hline Currently involved & $-0.22^{* * *}$ & $-0.12^{*}$ & $-0.20^{* * *}$ & $-0.20^{* * *}$ & $0.15^{* *}$ \\
\hline Number Facebook friends & $0.08^{*}$ & 0.01 & 0.03 & 0.05 & -0.02 \\
\hline Offline contact & $0.21^{* * *}$ & -0.04 & $0.18^{* * *}$ & $0.19^{* * *}$ & -0.06 \\
\hline$R^{2}$ & $0.44^{* * *}$ & $0.38^{* * *}$ & $0.34^{* * *}$ & $0.43^{* * *}$ & $0.21^{* * *}$ \\
\hline \multicolumn{6}{|l|}{ Step 2} \\
\hline Facebook friends with ex & -0.05 & $-0.11^{*}$ & $-0.10^{*}$ & $-0.10^{*}$ & $-0.12^{*}$ \\
\hline Facebook Surveillance & $0.39 * * *$ & $0.16^{* *}$ & $0.36^{* * *}$ & $0.47^{* * *}$ & $-0.12^{*}$ \\
\hline$R^{2}$ & $0.54^{* * *}$ & $0.40^{* * *}$ & $0.42^{* * *}$ & $0.58^{* * *}$ & $0.24^{* * *}$ \\
\hline$R^{2} \triangle$ & $0.10^{* * *}$ & $0.02^{* *}$ & $0.08^{* * *}$ & $0.15^{* * *}$ & $0.03^{* *}$ \\
\hline
\end{tabular}

${ }^{\dagger} p<0.10,{ }^{*} p<0.05,{ }^{* *} p<0.01,{ }^{* * *} p<0.001$.

predictors entered at Step 1. Contrary to Hypothesis 1, remaining Facebook friends with the ex-partner was negatively associated with negative feelings, desire, and longing for the ex-partner. In support of Hypothesis 1, however, remaining Facebook friends was associated with lower personal growth. Consistent with Hypothesis 2, Facebook surveillance was positively related to current distress, negative feelings, desire, and longing for the ex-partner, and negatively related to personal growth.

\section{Discussion}

Taken together, these findings suggest that continued online exposure to an ex-romantic partner may inhibit postbreakup recovery and growth, even after accounting for the contribution of offline exposure and well-established personality and relational predictors. Notably, frequent monitoring of an ex-partner's Facebook page and list of friends, even when one was not a Facebook friend of the ex-partner, was associated with greater current distress over the breakup, negative feelings, sexual desire, longing for the ex-partner, and lower personal growth. These findings mirrored the correlates of offline contact, which was associated with greater current distress, sexual desire, and longing for the ex-partner, consistent with previous research. ${ }^{10}$ Facebook surveillance, therefore, accounted for aspects of postbreakup adjustment-negative feelings toward the ex-partner and lower personal growth-that offline contact did not. Importantly, these findings suggest that weak-tie contact with an ex-partner through Facebook contributed to poorer postbreakup functioning over and above strong-tie contact. Consistent with the view that weak-tie contact can supply information beyond strong-tie contact, ${ }^{12}$ Facebook may furnish information about an ex-partner that only intensifies heartbreak, such as news that the former partner is involved in a new relationship.
Contrary to expectations, people who remained Facebook friends with an ex-partner were lower in negative feelings, sexual desire, and longing for the former partner than people who were not Facebook friends. Although it seems likely that people who remained Facebook friends may have had weaker feelings for their partner before the breakup or experienced a more amicable split than people who had defriended the ex-partner, remaining Facebook friends was not significantly correlated with previous feelings for the expartner or breakup distress. An alternative possibility is that unbidden exposure to the potentially banal status updates, comments, and photos of an ex-partner through remaining Facebook friends may have decreased any residual attraction to the ex-partner. Former partners with whom we are no longer in contact, by contrast, may remain shrouded in an alluring mystique, suggesting that remaining Facebook friends with an ex-partner may actually help rather than harm one's postbreakup recovery.

Even so, people who remained Facebook friends were lower in personal growth than were those who had defriended the ex-partner, suggesting that even weak-tie contact with an ex-partner through remaining Facebook friends might disrupt the process of moving on. Although one might expect that the lower negativity, sexual desire, and longing for the ex-partner reported by participants who remained Facebook friends would be accompanied by greater, not lesser, personal growth, the former variables were not significantly correlated with personal growth. This lack of association is consistent with research that has found weak or nonsignificant relationships between indices of adjustment and personal growth following a traumatic event, ${ }^{21,22}$ suggesting that recovery and growth may be relatively independent processes. Indeed, healing from a relationship loss entails a process of recovering from negative emotions and detaching from the former partner, but also of developing a meaning-making narrative that enables personal growth. ${ }^{23}$ 
Thus, while remaining Facebook friends may benefit the breakup recovery process by mitigating negative emotions, desire, and longing for the ex-partner, it may simultaneously impede the construction of a personal growth-enhancing narrative.

The most notable limitation of this study is that the correlational design did not allow conclusions to be drawn about casual direction. Although these results suggested that offline contact and Facebook surveillance lead to poorer postbreakup adjustment and lower personal growth, it is just as plausible that people who were hung up on an ex-partner were more likely to seek them out in person and engage in greater Facebook surveillance, which in turn sustained the pining for the former partner. Likewise, people who stagnated after a breakup rather than experienced personal growth may have been more likely to retain the ex-partner as a Facebook friend. An experiment that compares participants who are encouraged not to check their ex-partner's Facebook page for a period of time with other participants who may check freely could shed light on whether Facebook surveillance is causally related to poorer postbreakup adjustment and growth. Furthermore, while it was beyond the scope of the current article to examine the motives behind remaining Facebook friends with an ex-partner and engaging in Facebook surveillance, these motives could be profitably explored in future research. For example, people who feel betrayed by an ex-partner tend to experience heightened breakup distress, ${ }^{8}$ and the current findings linked breakup distress with a greater likelihood of engaging in Facebook surveillance (see Table 2). Perhaps, then, people are more likely to engage in Facebook surveillance if a former partner has been unfaithful.

In spite of the need for further research, the take-home message from the present study is that keeping tabs on an expartner through Facebook is associated with poorer emotional recovery and personal growth following a breakup. Therefore, avoiding exposure to an ex-partner, both offline and online, may be the best remedy for healing a broken heart.

\section{Author Disclosure Statement}

No competing financial interests exist.

\section{References}

1. Joinson AN. (2008) 'Looking at', 'looking up' or 'keeping up with' people? Motives and uses of Facebook. In Proceedings of the 26th Annual SIGCHI Conference on Human Factors in Computing Systems (Florence, Italy, April 5-10, 2008), CHI'08. New York: ACM, pp. 1027-1036.

2. Marshall TC, Bejanyan K, Di Castro G, et al. Attachment styles as predictors of Facebook-related jealousy and surveillance in romantic relationships. Personal Relationships; DOI: 10.1111/ j.1475-6811.2011.01393.X.

3. Chaulk K, Jones T. Online obsessive relational intrusion: further concerns about Facebook. Journal of Family Violence $2011 ; 26: 245-254$.

4. Lyndon A, Bonds-Raacke J, Cratty AD. College students' Facebook stalking of ex-partners. Cyberpsychology, Behavior, and Social Networking 2011; 14:711-716.

5. Tokunaga RS. Social networking site or social surveillance site? Understanding the use of interpersonal electronic surveillance in romantic relationships. Computers in Human Behavior 2011; 27:705-713.
6. Bowe G. Reading romance: the impact Facebook rituals can have on a romantic relationship. Journal of Comparative Research in Anthropology and Sociology 2010; 1:61-77.

7. Spitzberg BH, Cupach WR. What mad pursuit? Obsessive relational intrusion and stalking related phenomena. Aggression and Violent Behavior 2003; 8:345-375.

8. Field T, Diego M, Pelaez M, et al. Breakup distress in university students. Adolescence 2009; 44:705-727.

9. Knox D, Zusman ME, Kaluzny M, et al. College student recovery from a broken heart. College Student Journal 2000; 34:322-324.

10. Sbarra DA, Emery RE. The emotional sequelae of nonmarital relationship dissolution: analysis of change and intraindividual variability over time. Personal Relationships 2005; 12:213-232.

11. Stefanone MA, Lackaff D, Rosen D. Contingencies of selfworth and social-networking-site behavior. Cyberpsychology, Behavior, and Social Networking 2011; 14:41-49.

12. Granovetter $M$. The strength of weak ties. American Journal of Sociology 1973; 78:1360-1379.

13. Davis D, Shaver PR, Vernon ML. Physical, emotional, and behavioral reactions to breaking up: the roles of gender, age, environmental involvement, and attachment style. Personality and Social Psychology Bulletin 2003; 29:971-884.

14. Rosenberg M. (1965) Society and the adolescent self-image. Princeton: Princeton University Press.

15. Fraley RC, Waller NG, Brennan KG. An item response theory analysis of self-report measures of adult attachment. Journal of Personality and Social Psychology 2000; 78:350-365.

16. Fletcher GJO, Simpson JA, Thomas G. The measurement of perceived relationship quality components: a confirmatory factor analytic approach. Personality and Social Psychology Bulletin 2000; 26:340-354.

17. Saffrey C, Ehrenberg M. When thinking hurts: attachment, rumination, and postrelationship adjustment. Personal Relationships 2007; 14:351-368.

18. Wegner DM, Gold DB. Fanning old flames: emotional and cognitive effects of suppressing thoughts of a past relationship. Journal of Personality and Social Psychology 1995; 68:782-792.

19. Tedeschi RG, Calhoun LG. The Post-Traumatic Growth Inventory: measuring the positive legacy of trauma. Journal of Traumatic Stress 1996; 9:455-471.

20. Tashiro T, Frazier P. "I'll never be in a relationship like that again": personal growth following romantic relationship breakups. Personal Relationships 2003; 10:113-128.

21. Proffitt D, Cann A, Calhoun LG, et al. Judeo-Christian clergy and personal crisis: religion, posttraumatic growth and well-being. Journal of Religion and Health 2007; 46: 219-231.

22. Triplett KN, Tedeschi RG, Cann A, et al. Posttraumatic growth, meaning in life, and life satisfaction in response to trauma. Psychological Trauma: Theory, Research, Practice, and Policy 2012; 4:400-410.

23. Stroebe M, Schut H. The dual process model of coping with bereavement: rationale and description. Death Studies 1999; 23:197-224.

Address correspondence to: Dr. Tara C. Marshall Department of Psychology School of Social Sciences Brunel University Uxbridge UB8 3PH United Kingdom

E-mail: tara.marshall@brunel.ac.uk 